\title{
The pitfalls of short-range endemism: high vulnerability to ecological and landscape traps
}

\author{
Leanda D Mason ${ }^{\text {Corresp.. }}{ }^{1}$ ， Philip W Bateman ${ }^{1}$, Grant W Wardell-Johnson ${ }^{1}$ \\ ${ }^{1}$ School of Molecular and Life Sciences, Curtin University of Technology, Perth, Western Australia, Australia \\ Corresponding Author: Leanda D Mason \\ Email address: leanda.mason@curtin.edu.au
}

Ecological traps attract biota to low-quality habitats. Landscape traps are zones caught in a vortex of spiraling degradation. Here, we demonstrate how short-range endemic traits may make such taxa vulnerable to ecological and landscape traps. Three short-range endemic species of mygalomorph spider were used in this study: Idiommata blackwalli, Idiosoma sigillatum and an undescribed Aganippe sp. Mygalomorphs can be long-lived (> 40 years) and select sites for permanent burrows in their early dispersal phase. Spiderlings from two species, I. blackwalli $(n=20)$ and Aganippe sp. $(n=50)$, demonstrated choice for microhabitats under experimental conditions, that correspond to where adults typically occur in situ. An invasive veldt grass microhabitat was selected almost exclusively by spiderlings of $I$. sigillatum. At present, habitat dominated by veldt grass in Perth, Western Australia, has lower prey diversity and abundance than undisturbed habitats and therefore may act as an ecological trap for this species. Furthermore, as a homogenising force, veldt grass can spread to form a landscape trap in naturally heterogeneous ecosystems.

Selection of specialised microhabitats of short-range endemics may explain high extinction rates in old, stable landscapes undergoing (human-induced) rapid change. 
1 The pitfalls of short-range endemism: high vulnerability to ecological and

2 landscape traps

3

4 Author: Leanda Denise Mason ${ }^{1 *}$, Philip W. Bateman ${ }^{1}$ and Grant Wardell-Johnson ${ }^{1}$

5 1. Curtin University, School of Molecular and Life Sciences, Kent St, Bentley, Perth, WA, AUS 6102

$7 \quad{ }^{*}$ Corresponding author email: leanda.denise.mason@gmail.com 
9 Abstract

10 Ecological traps attract biota to low-quality habitats. Landscape traps are zones caught

11 in a vortex of spiraling degradation. Here, we demonstrate how short-range endemic

12 traits may make such taxa vulnerable to ecological and landscape traps.

13 Three short-range endemic species of mygalomorph spider were used in this study:

14 Idiommata blackwalli, Idiosoma sigillatum and an undescribed Aganippe sp.

15 Mygalomorphs can be long-lived ( $>40$ years) and select sites for permanent burrows in 16 their early dispersal phase.

17 Spiderlings from two species, I. blackwalli $(\mathrm{n}=20)$ and Aganippe sp. $(\mathrm{n}=50)$,

demonstrated choice for microhabitats under experimental conditions, that correspond to where adults typically occur in situ. An invasive veldt grass microhabitat was selected almost exclusively by spiderlings of $I$. sigillatum.

At present, habitat dominated by veldt grass in Perth, Western Australia, has lower prey diversity and abundance than undisturbed habitats and therefore may act as an ecological trap for this species. Furthermore, as a homogenising force, veldt grass can spread to form a landscape trap in naturally heterogeneous ecosystems.

Selection of specialised microhabitats of short-range endemics may explain high extinction rates in old, stable landscapes undergoing (human-induced) rapid change.

\section{Introduction}

Habitat-selection theory suggests behavioural and life history decisions prompted by environmental cues act as indicators of habitats that maximise fitness (Rosenzweig, 1981). Misguided habitat choice may be based on environmental cues associated with 
32 high-quality habitats but that are no longer reliable in disturbed or changing

33 environments. Choices based on such cues lead to organisms entering 'ecological

34 traps' (Delibes, Gaona \& Ferreras, 2001; Dwernychuk \& Boag, 1972). Ecological traps

35 pose a serious conservation concern for a wide range of taxa (Battin, 2004; Hale \&

36 Swearer, 2016; Hale, Treml \& Swearer, 2015). A review of ecological traps shows that

37 historically, most studies have focused on highly mobile bird species and their choice of

38 nesting sites but more recently there has been attention to other, commercially relevant,

39 taxa (Robertson, Rehage \& Sih, 2013). Here we argue that ecological traps are

40 particularly threatening for short-range endemic (SRE) taxa. Persistence of these taxa is

41 further compromised in disturbed landscapes for two main reasons 1) their specialist co-

42 evolutionary requirements, and 2) limitations in their capacity to relocate following

43 disturbance.

44

45

46

47

48

49

50

51

52

53

54

Highly disturbed landscapes form 'landscape traps', compromising ecological function and compounding the influence of ecological traps for many taxa (Lindenmayer et al., 2011). For example, logging and altered fire regimes can interact in ways that cause the irreversible modification of ecological function. Landscape traps may also be associated with negative feedback loops between fire and weed invasion (Fisher, Loneragan, Dixon, Delaney, et al., 2009). Thus, fire provides opportunity for weed invasion, which then provides greater fuel loads, increasing the capacity for more intense fires.

3 Regions with high proportions of endemic taxa represent a unique and ongoing 54 challenge in conservation biology worldwide (Wardell-Johnson \& Horwitz, 1996). 
55 Landscape age may explain high endemism and biodiversity in some sites (Mucina \&

56 Wardell-Johnson, 2011) with complex microhabitats and niche partitioning having

57 established and evolved over time in stable conditions (Rosenzweig, 1981). Old, stable

58 landscapes may therefore be more susceptible to landscape traps due to increased

59 numbers of associations - providing a higher chance of disturbances that lead to

60 negative feedback loops (Lindenmayer et al., 2011). Historical divergence in old, stable

61 landscapes may be primarily attributed to two major factors 1) heterogeneously

62 distributed habitat and narrow, subdued geographical barriers (Wardell-Johnson \&

63 Horwitz, 1996), and 2) taxa with limited mobility and dispersal capabilities (Rix et al., 64 2014).

65

A taxon with a distribution of less than $10000 \mathrm{~km}^{2}$; low reproductive output and limited

67 mobility and dispersal are criteria for SRE taxa (Harvey, 2002). SREs are of high

68 conservation concern as a restricted distribution contributes to rarity and increased

69 chance of extinction (Harvey, 2002; Rabinowitz, 1981). Vulnerability is exacerbated

70 when combined with a limited capacity to adapt or escape human-induced rapid

71 environmental change (HIREC) (Sih, Ferrari \& Harris, 2011). SREs tend to be

72 specialists, and representation is proportionally higher in invertebrates than vertebrates

73 (Harvey, 2002). Old, stable landscapes are likely to have the highest numbers and

74 proportions of SREs globally (Rix et al., 2014).

75

76 The ancient and highly heterogeneous landscape of south-western Australia (SWA)

77 hosts many SRE species (Rix et al., 2016). By their nature, SREs are typically rare and 
78 cryptic, making it difficult to gather essential information for conservation decisions.

79 Poor dispersal capabilities suggest that SREs are able to survive in small patches of

80 high-quality remnant vegetation (Mason, Wardell-Johnson \& Main, 2016). Mygalomorph

81 spiders are excellent candidate taxa as bioindicators for SRE taxa. They are sedentary,

82 meaning individuals can be monitored long-term. Choice of microhabitat by a dispersing

83 spiderling is a vital first step to successful investment in a life-long burrow. Burrows are

84 investments in terms of effort and time to establish. It is rare for mygalomorphs to move

85

86

87

89

90

91

92

93

94

95

96

97

98

99

as adults, as such moves come at high energy cost and leave them vulnerable to predation and desiccation (Mason et al., 2013). As mygalomorph matriarchs can live up to 40 years (Main unpublished data; cited in Rix et al. 2016), appropriate burrow-site and habitat choice by spiderlings is vital.

We aimed to determine whether mygalomorph spiderlings of three species display choice of microhabitat conditions that reflects their realised niche as adults. Realised niche was recorded as adult burrow microhabitats that were regularly recorded during an extensive survey. Burrow microhabitats of adults of each species were used to inform the microhabitat habitat preference choices provided to all spiderling species. Mason et al., (2016) suggested that invasive veldt grass (Erharta spp.) may be detrimental to local mygalomorph species, either through preventing establishment of burrows, or through microhabitat or prey availability variables. Veldt grass was therefore made available as one of four ground cover choices for mygalomorph spiderlings in a controlled field trial. Microhabitat variables of relative humidity $(\mathrm{RH})$, ambient 
100 temperature (Ta) and prey species assemblages (PSA) were also measured to explain 101 spiderling choice.

102

103 Methods

104

105 Study site

106 This study was conducted in Perth, a highly urbanised centre in the Mediterranean-

107 climate zone (mean annual rainfall $740 \mathrm{~mm}$ ) of SWA. This highly biodiverse region has

108 lost almost $90 \%$ of the original habitat due to extensive deforestation and on-going

109 disturbance, qualifying it as a global biodiversity hotspot (Myers et al., 2000;

110 Wardell-Johnson et al., 2016).

111

\section{Study species}

113 We collected an individual Idiommata blackwalli (Barychelidae - brush-footed trapdoor

114 spiders, body length: $32 \mathrm{~mm}$ ) with a brood size of 42 and individuals of two genera of

115 Idiopodae (armoured trapdoor spiders); an Aganippe sp. (body length: $27 \mathrm{~mm}$ ) and an

116 Idiosoma sigillatum (body length: $36 \mathrm{~mm}$ ) which had broods of 65 and 78 , respectively.

117 The idiopid spiderlings were approximately $3 \mathrm{~mm}$ in length and those of $I$. blackwalli 7

$118 \mathrm{~mm}$ long.

119 Despite large superficial differences between Aganippe and Idiosoma, genetic

120 techniques have recently found these genera to be closely related. The extreme

121 sclerotisation of the abdomens of I. sigillatum likely relates to behaviour where they

122 block their burrow against intruders. Burrow morphology supports this behaviour by 
123 having a diagonistic 'atrium' where the spider can manoeuvre near their lid burrow

124 during foraging, but tightly constricts down the shaft. Foraging range is thought to be

125 enhanced for I.sigillatum due to their burrows having twig-line attachments; this enables

126 them to detect prey species along the twigs via vibrations. Both Aganippe and Idiosoma

127 are highly defensive of their burrows, retreating to the bottom and rearing when

128 disturbed. Conversely, the I.blackwalli collected was quite docile by comparison and

129 easily observable in her shallow (15 cm deep) bulb-shaped burrow. Photos of each

130 spider species and their typical burrow entrance has been provided for comparison

131 (Figure 1).

132

133 Microhabitat preference

134 Adult spider burrows were located during an extensive survey of Perth urban remnant

135 vegetation that included 135 quadrats $(100 \mathrm{~m} \times 100 \mathrm{~m})$ in 41 sites (see Mason et al.

1362016 for further details). Microhabitat variables to included leaf litter cover (\%) and leaf

137 litter type within a one metre square quadrat centred on burrows.

138

139 To reflect the natural dispersal time of mygalomorph species a habitat preference

140 experiment was conducted, using the collected spiderlings, from $24^{\text {th }}$ April to $24^{\text {th }}$ May in

141 the field trials area at Curtin University (Bentley campus). Fifty circular enclosures 10

$142 \mathrm{~cm}$ high and $30 \mathrm{~cm}$ in diameter were constructed from clear plastic, sunk three

143 centimetres into the sand and sealed with cling-wrap to deter spiderling escape. Four

144 microhabitat treatments were provided within these enclosures; bare soil, veldt grass

145 tufts, Allocasuarina fraseriana (Casuarinaceae) and Banksia attenuata (Proteaceae) 
146 litter. Within each enclosure, configuration of microhabitats was divided into eighths with

147 the two replicate treatments positioned directly opposite one another. An individual

148 spiderling was released in the centre of each enclosure and the location of their burrow

149 recorded on the following day. Chi-square tests were performed for each species using

150 StatistXL v.1.9 to identify microhabitat preference, both in adults and by dispersing

151 spiderlings.

152

153 Microhabitat characteristics

154 Ambient temperature $(\mathrm{Ta})$ and relative humidity $(\mathrm{RH})$ was recorded hourly using

155 iButtons in each of the four microhabitat types in the field; bare ground, veldt grass tufts,

156 leaf litter of $A$. fraseriana and leaf litter of $B$. attenuata. Ten iButtons were placed in each

157 microhabitat type at two remnant bushland study sites (Kings Park: 3157'46.0"S 115

$158{ }^{\circ} 49^{\prime} 52.8^{\prime \prime E}$ and Bold Park: 31056'53.1”S 11546'13.6”E) and at the spiderling experiment

159 field trial area $\left(32^{\circ} 00^{\prime} 43.1^{\prime \prime} \mathrm{S} 115^{\circ} 53^{\prime} 23.1^{\prime \prime} \mathrm{E}\right)$. All iButtons were placed where leaf litter

160 and top layer of soil interacted, except for bare soil microhabitats where iButtons were

161 placed on top of the soil. Records of Ta and RH during 24 $4^{\text {th }}$ May to $6^{\text {th }}$ June 2016 were

162 used for analysis.

163 To assess abundance and diversity of potential prey species, we collected twenty in situ

164 ground-cover samples for each of the four microhabitats; ten from Bold Park and ten

165 from Kings Park. Samples were collected within a $20 \mathrm{~cm} \times 20 \mathrm{~cm}$ quadrat and were

166 pooled from the same microhabitat and site. Samples were placed in a light-funnel for a

167 week and leaf-litter invertebrates were collected in a jar filled with $100 \mathrm{~mL}$ of ethylene- 
168 glycol. These invertebrates were later categorised by size and recognisable taxonomic 169 units (RTUs) (Oliver \& Beattie, 1993).

170

171 Results

172

173 Microhabitat preference

174 Significant differences in microhabitat preference were found for all three species. Adult 175 microhabitat corresponded with spiderling microhabitat preferences for both Aganippe 176 sp. and I. blackwalli; spiderlings of these two species preferred open ground cover and 177 B. attenuata leaf litter, respectively (Table 1).

178 179 180 Idiosoma sigillatum, a species that typically attaches twig-lines to the rim of their burrow, were predominately found in $A$. fraseriana leaf litter as adults, but selected veldt grass almost exclusively as spiderlings (Table 1). In these cases, no twig-lining was apparent, with one exception where Allocasuarina litter from an adjacent treatment was used.

\section{Microhabitat characteristics}

185 A comparison between microhabitat Ta revealed little difference, with all averaging between $14^{\circ} \mathrm{C}$ and $15^{\circ} \mathrm{C}$. Variability in Ta remained most stable in $B$. attenuata leaf litter (range: 23.0, SD: 3.9), followed by veldt grass (range: 23.2, SD: 4.2), A. fraseriana leaf litter (range: 23.3, SD: 4.5) and bare ground (range: 26.0, SD: 5.3) (Figure 2).

190 Relative humidity exposed far greater difference between microhabitats. Leaf litter of $B$.

191 attenuata, leaf litter of $A$. fraseriana and open ground cover all averaged $87.2-87.4 \%$. 
192 However, a higher RH (93\%) was found in veldt grass. Veldt grass retained the most

193 moisture (range: 51.7, SD: 10.5), followed by leaf litter of $B$. attenuata (range: 62.9 , SD:

194 12.6), leaf litter of $A$. fraseriana (range: 43.8, SD: 10.6) and open ground (range: 72.2,

195 SD: 15.5) (Figure 3).

196

197 The size of potential prey species varied greatly between microhabitat types. Size

198 classes of $1 \mathrm{~mm}$ and $10 \mathrm{~mm}$ yielded high numbers (i.e. $<100$ individuals) across all

199 microhabitats and can be attributed primarily to two RTUs being Collembola

200 (springtails). Veldt grass yielded the least potential prey in both abundance and species

201 richness (n: 213, S: 10). By comparison, open ground had greater numbers (n: 483) but

202 similar species richness (S: 11) while Banksia leaf litter provided more species (S: 21),

203 but lower abundance ( $\mathrm{n}: 393$ ) than open ground. The most productive ground cover was

204 A. fraseriana with both highest abundance (n: 6591) and richness (S: 23) (see

205 Supplementary Materials).

206

207 Discussion

208

209 Habitat choices consistent with an ecological trap were revealed by I. sigillatum

210 spiderlings, as they showed a high preference for invasive veldt grass over native $A$.

211 fraseriana leaf litter (where adults were typically found). Idiosoma sigillatum spiderlings

212 appeared to have fallen into an ecological trap, as indicated by five factors. Firstly, a

213 high $\mathrm{RH}$ in veldt grass may have enticed the spiderlings into this microhabitat. High RH

214 may be an evolutionary trap for this species, as high $\mathrm{RH}$ is a physiological requirement 
215 for mygalomorphs (Mason et al., 2013). Secondly, l. sigillatum is one of a few

216 mygalomorph species in SWA that have a "moustache" twig-line arrangement attached

217 to their burrow rim. This is apparent even as spiderlings when establishing in $A$.

218 fraseriana leaf litter. Foraging capabilities may therefore be further compromised when

219 establishing in veldt grass. Thirdly, previous studies have indicated that veldt grass

220 compromises ecosystem functioning (Fisher et al., 2006) and this appears to be

221 supported by our data on low prey species abundance and diversity in veldt grass in

222 comparison to A. fraseriana. Fourthly, if, in the wild, I. sigillatum spiderlings disperse

223 into veldt grass patches, then there is no evidence they have persisted to adults. Lastly,

224 should spiderlings initially establish in veldt grass and then move, this would result in

225 high energy costs, and leave them vulnerable to predation and desiccation.

226

227 Mygalomorph spiders have exceptionally low fecundity, rendering the probability of 228 locating a brooding mygalomorph spider mother during single surveys very low.

229 Therefore, we were exceptionally fortunate to conduct this study using three individual

230 broods from three species. While there is potential for maternal effects on habitat

231 preference, life history and realised niches of mygalomorph adults suggest a low

232 likelihood of a change in outcome. Our confirmation of mygalomorph spiderling choice

233 in microhabitats is novel. We therefore suggest investigation in other mygalomorph

234 spiders with ready access to brood, such as tarantulas that are routinely used in the pet 235 trade.

236 
237 The impact of invasive grasses effectively transforms and homogenises the ecosystem.

238 By facilitating and interacting with other transforming processes (e.g. nutrient status and

239 fire regime) these grasses form a landscape trap (Fisher, Loneragan, Dixon \&

240 Veneklaas, 2009). Reliance on microhabitats, as demonstrated by Aganippe sp. and $I$.

241 blackwalli, and other SRE species (Harvey et al., 2011), means that the spread of veldt

242 grass to form a landscape trap is likely to be a threatening process (Figure 4).

243

244 As an invasive weed, veldt grass tends to homogenise environments by out-competing

245 native species (Fisher, Loneragan, Dixon \& Veneklaas, 2009) and replacing

246 microhabitats. In highly heterogeneous environments that harbour a high diversity of

247 specialist, endemic and co-evolved taxa, homogenisation poses a significant threat to

248 biodiversity (Wardell-Johnson \& Horwitz, 1996). Homogenisation of previously

249 heterogeneous habitats is the underlying cause for biodiversity loss worldwide. This has

250 particular significance for the transformation of native habitats through human land-use

251 practices (Sih et al., 2011). In terms of effective management, re-introduction of native

252 species into habitats after a homogenising disturbance would be a poor use of

253 resources (Fisher, Loneragan, Dixon \& Veneklaas, 2009). Preventative rather than

254 restorative measures is required (Wardell-Johnson et al., 2016). Restoration is

255 impracticable for the level and time required to rebuild complexity and associated

256 microhabitats (Rebelo et al., 2011). The prevention of likely ecological traps and

257 determination of the circumstances that transform them into landscape traps is

258 imperative for conservation decision-making. 
260 Sedentary taxa enable reliable monitoring of individuals and populations, generating

261 invaluable data for conservation decision-making (Main, 1978). The majority of

262 mygalomorph species exhibit the SRE traits of low mobility, low dispersal, low fecundity,

263 slow growth, restriction to particular habitats, and entire distribution being less than 10

$264000 \mathrm{~km}^{2}$ (Harvey, 2002). Some mygalomorph species have capacity to balloon (Pétillon

265 et al., 2012), but this may have evolved to mitigate territorial behaviour (Mason

266 unpublished data) rather than to increase dispersal capability. As such, the biology of

267 particular SRE groups will still need to be considered in management for conservation.

268 Mygalomorphs provide an excellent exemplar of how other SRE may react to novel

269 threatening processes. Unfortunately, exceptionally long lifespan and low reproductive

270 output mean that reduction in fitness, through habitat clearance, disturbance and

271 degradation e.g. through weed invasions, may already be causing localised extinctions

272 in mygalomorphs and other SREs (Rix et al., 2016).

273

274 We found invasive veldt grass to be a poor-quality microhabitat compared to native

275 microhabitats. Veldt grass provides an example of ecological and landscape traps in

276 which SRE taxa, such as mygalomorphs, may be caught. In a global context, all

277 specialist species that cannot readily re-locate or adapt are particularly vulnerable to the

278 formation of landscape traps through homogenisation of native microhabitats. While

279 broad-scale management would be ineffective in heterogeneous environments

280 (Wardell-Johnson \& Horwitz, 1996), targeting specific, widespread traps, such as weed

281 invasion, may control homogenisation and consequent extinctions. 
283

284

285

286

287

288

289

290

291

292

293

294

295

296

297

298

299

300

301

302

303

304

305

306

307

308

309

310

311

312

313

314

\section{Conclusion}

Informed justification allows cost-effective investment in conservation decision-making.

Human-induced rapid environmental change is a significant threat to biodiversity in old, stable landscapes, which are prevalent globally (Mucina \& Wardell-Johnson, 2011).

Ecosystem functioning will inevitably be compromised and SRE species will go extinct without appropriate conservation management. Identifying potential ecological and landscape traps early will allow us to better manage SREs and other specialist taxa prevalent in heterogeneous habitats. Further studies into the interactions between taxa traits and disturbance will allow more effective management, potentially curtailing impacts of current threatening processes.

\section{References}

Battin, J. (2004) When good animals love bad habitats: ecological traps and the conservation of animal populations, Conservation Biology, 18, 6, 1482-91.

Delibes, M., Gaona, P. \& Ferreras, P. (2001) Effects of an attractive sink leading into maladaptive habitat selection, The American Naturalist, 158, 3, 277-85.

Dwernychuk, L. \& Boag, D. (1972) Ducks nesting in association with gulls-An ecological trap?, Canadian Journal of Zoology, 50, 5, 559-63.

Fisher, J.L., Loneragan, W.A., Dixon, K., Delaney, J. \& Veneklaas, E.J. (2009) Altered vegetation structure and composition linked to fire frequency and plant invasion in a biodiverse woodland, Biological Conservation, 142, 10, 2270-81.

Fisher, J.L., Loneragan, W.A., Dixon, K. \& Veneklaas, E.J. (2009) Soil seed bank compositional change constrains biodiversity in an invaded species-rich woodland, Biological Conservation, 142, 2, 256-69.

Fisher, J.L., Veneklaas, E.J., Lambers, H. \& Loneragan, W.A. (2006) Enhanced soil and leaf nutrient status of a Western Australian Banksia woodland community invaded by Ehrharta calycina and Pelargonium capitatum, Plant and Soil, 284, 1-2, 253-64.

Hale, R. \& Swearer, S.E. 2016, 'Ecological traps: current evidence and future directions', Proc. $R$. Soc. B, vol. 283, The Royal Society, p. 20152647. 
315

316

317

318

319

320

321

322

323

324

325

326

327

328

329

330

331

332

333

334

335

336

337

338

339

340

341

342

343

344

345

346

347

348

349

350

351

352

353

354

355

356

357
Hale, R., Treml, E.A. \& Swearer, S.E. (2015) Evaluating the metapopulation consequences of ecological traps, Proceedings of the Royal Society of London B: Biological Sciences, 282, 1804, 20142930.

Harvey, M.S. (2002) Short-range endemism in the Australian fauna: some examples from nonmarine environments, Invertebrate Systematics, 16, 555-70.

Harvey, M.S., Rix, M.G., Framenau, V.W., Hamilton, Z.R., Johnson, M.S., Teale, R.J., Humphreys, G. \& Humphreys, W.F. (2011) Protecting the innocent: studying short-range endemic taxa enhances conservation outcomes, Invertebrate Systematics, 25, 1, 1-10.

Lindenmayer, D.B., Hobbs, R.J., Likens, G.E., Krebs, C.J. \& Banks, S.C. (2011) Newly discovered landscape traps produce regime shifts in wet forests, Proceedings of the National Academy of Sciences, 108, 38, 15887-91.

Main, B.Y. (1978) Biology of the arid-adapted Australian trapdoor spider Anidiops villosus (rainbow), Bulletin of the British Arachnological Society, 4, 161-75.

Mason, L., Tomlinson, S., Withers, P. \& Main, B. (2013) Thermal and hygric physiology of Australian burrowing mygalomorph spiders (Aganippe spp.), Journal of Comparative Physiology B, 183, 1, 71-82.

Mason, L.D., Wardell-Johnson, G. \& Main, B.Y. (2016) Quality not quantity: conserving species of low mobility and dispersal capacity in south-western Australian urban remnants, Pacific Conservation Biology, 22, 1, 37-47.

Mucina, L. \& Wardell-Johnson, G.W. (2011) Landscape age and soil fertility, climatic stability, and fire regime predictability: beyond the OCBIL framework, Plant and soil, 341, 1-2, 123.

Myers, N., Mittermeier, R.A., Mittermeier, C.G., Da Fonseca, G.A. \& Kent, J. (2000) Biodiversity hotspots for conservation priorities, Nature, 403, 6772, 853-8.

Oliver, I. \& Beattie, A.J. (1993) A possible method for the rapid assessment of biodiversity, Conservation biology, 7, 3, 562-8.

Pétillon, J., Deruytter, D., Decae, A., Renault, D. \& Bonte, D. (2012) Habitat use, but not dispersal limitation, as the mechanism behind the aggregated population structure of the mygalomorph species Atypus affinis, Animal Biology, 62, 2, 181-92.

Rabinowitz, D. 1981, Seven forms of rarity, The Biological aspects of rare plant conservation,

Rebelo, A., Holmes, P., Dorse, C. \& Wood, J. (2011) Impacts of urbanization in a biodiversity hotspot: conservation challenges in Metropolitan Cape Town, South African Journal of Botany, 77, 1, 20-35.

Rix, M.G., Edwards, D.L., Byrne, M., Harvey, M.S., Joseph, L. \& Roberts, J.D. (2014) Biogeography and speciation of terrestrial fauna in the south-western Australian biodiversity hotspot, Biological Reviews.

Rix, M.G., Huey, J.A., Main, B.Y., Waldock, J.M., Harrison, S.E., Comer, S., Austin, A.D. \& Harvey, M.S. (2016) Where have all the spiders gone? The decline of a poorly known invertebrate fauna in the agricultural and arid zones of southern Australia, Austral Entomology.

Robertson, B.A., Rehage, J.S. \& Sih, A. (2013) Ecological novelty and the emergence of evolutionary traps, Trends in ecology \& evolution, 28, 9, 552-60.

Rosenzweig, M.L. (1981) A theory of habitat selection, Ecology, 62, 2, 327-35. 
358 Sih, A., Ferrari, M.C. \& Harris, D.J. (2011) Evolution and behavioural responses to

359

360

361

362

363

364

365

366

367

368 human-induced rapid environmental change, Evolutionary Applications, 4, 2, 367-87.

Wardell-Johnson, G. \& Horwitz, P. (1996) Conserving biodiversity and the recognition of heterogeneity in ancient landscapes: a case study from south-western Australia, Forest Ecology and Management, 85, 1, 219-38.

Wardell-Johnson, G., Wardell-Johnson, A., Bradby, K., Robinson, T., Bateman, P.W., Williams, K., Keesing, A., Braun, K., Beckerling, J. \& Burbridge, M. (2016) Application of a Gondwanan perspective to restore ecological integrity in the south-western Australian global biodiversity hotspot, Restoration Ecology. 


\section{Table $\mathbf{1}$ (on next page)}

Microhabitat preferences for three mygalomorph spider species (Aganippe sp., Idiommata blackwalli and Idiosoma sigillatum).

Spiderling preference was recorded under controlled experimental conditions in Perth, southwestern Australia. The number of adult burrows found in situ ground cover microhabitats (Allocasuarina, Banksia, bare ground, veldt grass) is shown. 
Microhabitat preferences for three mygalomorph spider species (Aganippe sp., Idiommata blackwalli and Idiosoma sigillatum). Spiderling preference was recorded under controlled experimental conditions in Perth, south-western Australia. The number of adult burrows found in situ ground cover microhabitats (Allocasuarina, Banksia, bare ground, veldt grass) is shown.

\begin{tabular}{|c|c|c|c|c|c|c|c|c|}
\hline & Species & Allocasuarina & Banksia & Bare ground & Veldt grass & $\mathrm{n}$ & d.f. & $p$ value \\
\hline \multirow{3}{*}{ 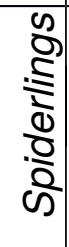 } & Aganippe sp. & 8 & 12 & 21 & 9 & 50 & 3 & 0.04 \\
\hline & Idiommata blackwalli & 3 & 11 & 3 & 3 & 20 & 3 & 0.01 \\
\hline & Idiosoma sigillatum & 2 & 0 & 0 & 38 & 40 & 3 & $<0.001$ \\
\hline \multirow{3}{*}{\begin{tabular}{l}
$n$ \\
\multirow{2}{T}{} \\
$\frac{0}{2}$
\end{tabular}} & Aganippe sp. & 1 & 2 & 10 & 0 & 13 & 3 & $<0.001$ \\
\hline & Idiommata blackwalli & 3 & 15 & 0 & 0 & 18 & 3 & $<0.001$ \\
\hline & Idiosoma sigillatum & 17 & 4 & 4 & 0 & 25 & 3 & $<0.001$ \\
\hline
\end{tabular}




\section{Figure 1}

Subject spider species and their burrows.

Three species of mygalomorph spider used in the study and their corresponding burrows; a) Idiosoma sigillatum, b) Idiomatta blackwalli and c) Aganippe sp. Scale bars in the bottom right corner of burrow photos refers to the widest point across the burrow entrance. All three species occur within patches of urban bushland within Perth, Western Australia. Photo credits: Bill Bateman for Aganippe sp. spider, Jessica Moran for Idiommata blackwalli spider and Leanda Denise Mason for all others.

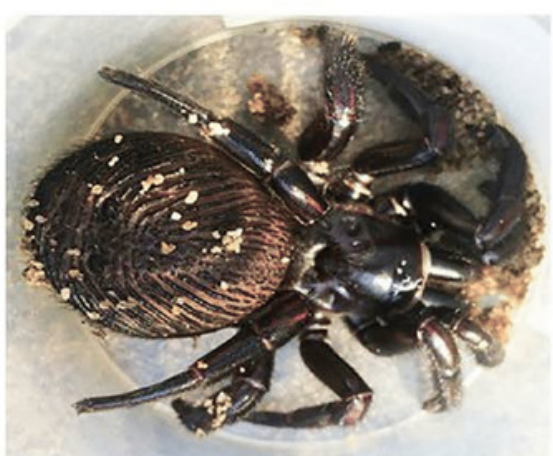

a) Idiosoma sigillatum

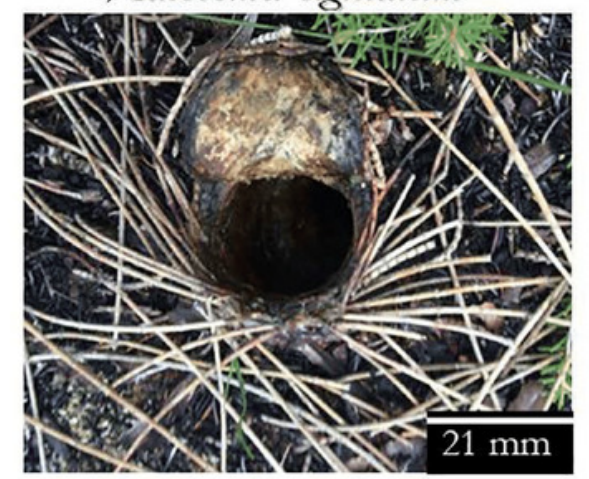

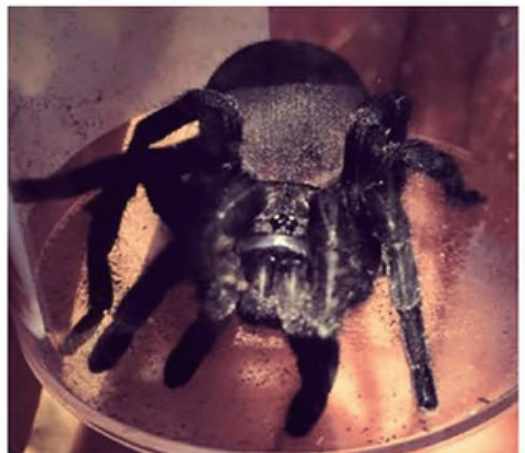

b) Idiommata blackwalli

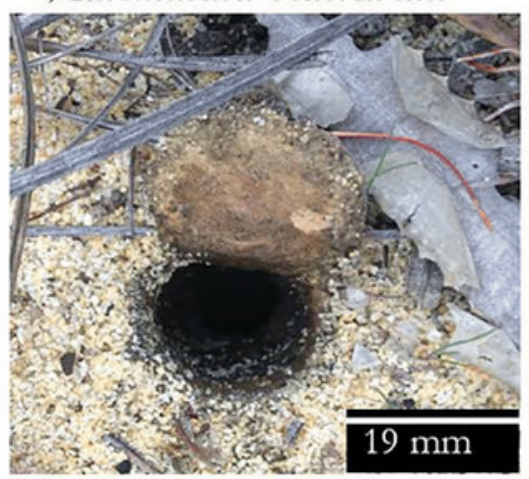

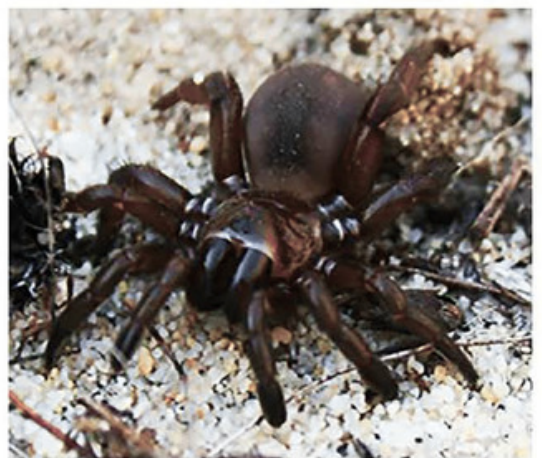

c) Aganippe sp.

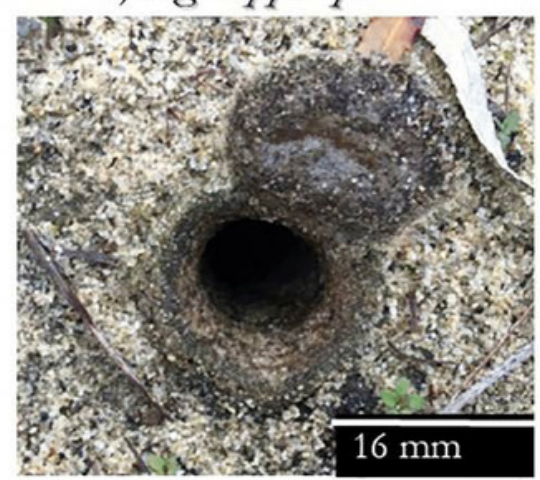


Figure 2

Ambient temperature fluctuation in microhabitats

A box-and-whisker plot comparing the differences in ambient temperature $\left(\mathrm{C}^{\circ}\right)$ fluctuation during $24^{\text {th }}$ May $-6^{\text {th }}$ June, 2016 in different ground cover types (Banksia leaf and Allocasuarina leaf litter, bare ground and veldt grass) found in urban bushland of Perth, Western Australia.

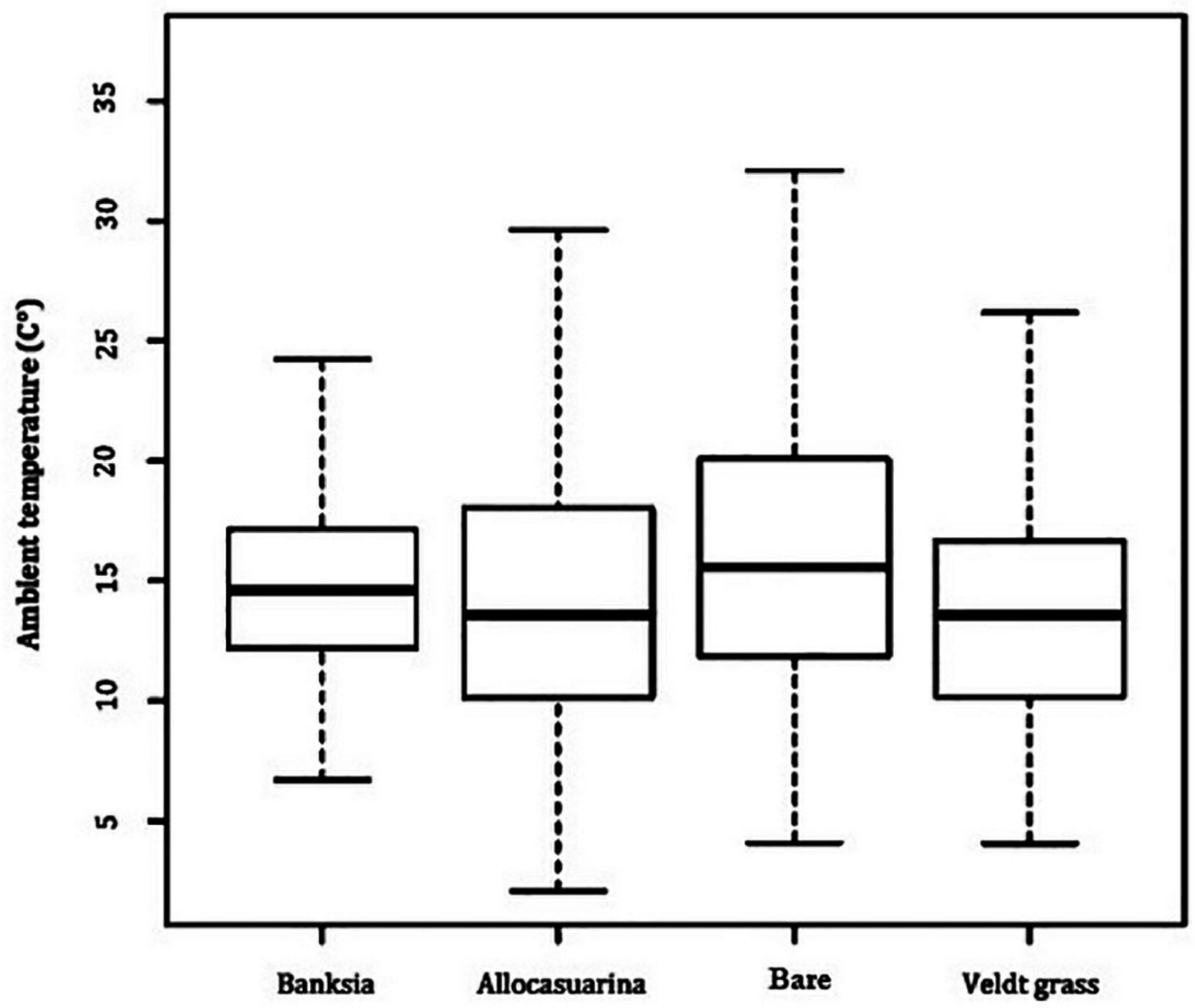

Ground cover type 
Figure 3

Relative humidity fluctuations in different microhabitats

A box-and-whisker plot comparing the differences in relative humidity (\%) fluctuation during $24^{\text {th }}$ May $-6^{\text {th }}$ June, 2016 in different ground cover types (Banksia leaf and Allocasuarina leaf litter, bare ground and veldt grass) found in urban bushland of Perth, Western Australia.

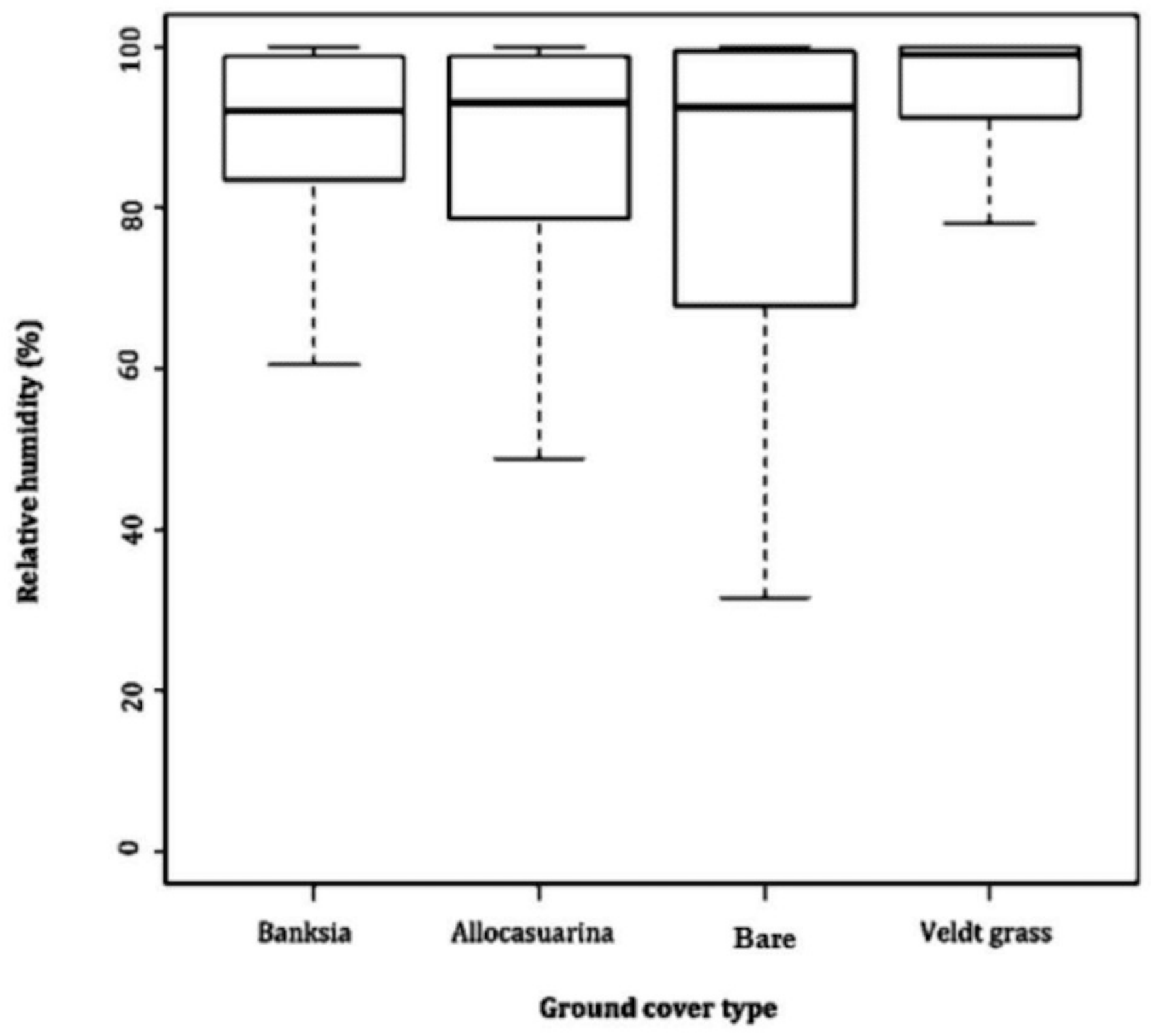


Figure 4(on next page)

Short-range endemics get caught in ecological and landscape traps

Hypothetical representation of short-range endemic species in response to ecological traps and landscape traps over time. The example, including all photographs, is from Bold Park in Perth metropolitan area of Western Australia. Photo credit: Leanda Denise Mason. 

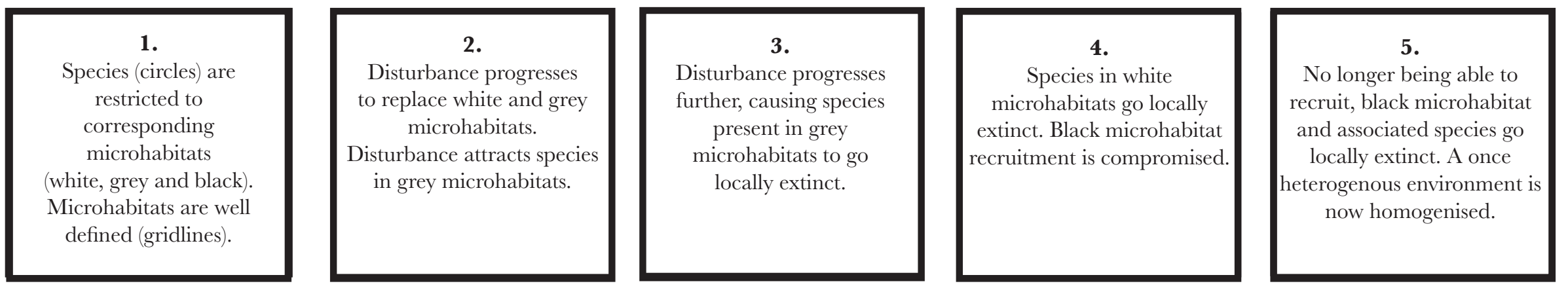

\begin{tabular}{|c|c|c|}
\hline $\begin{array}{l}0 \\
0\end{array}$ & $0_{0}$ & 00 \\
\hline 00 & $\begin{array}{l}0 \\
0\end{array}$ & ${ }_{0}$ \\
\hline${ }_{0}^{0}$ & 00 & $\begin{array}{l}0 \\
0\end{array}$ \\
\hline
\end{tabular}
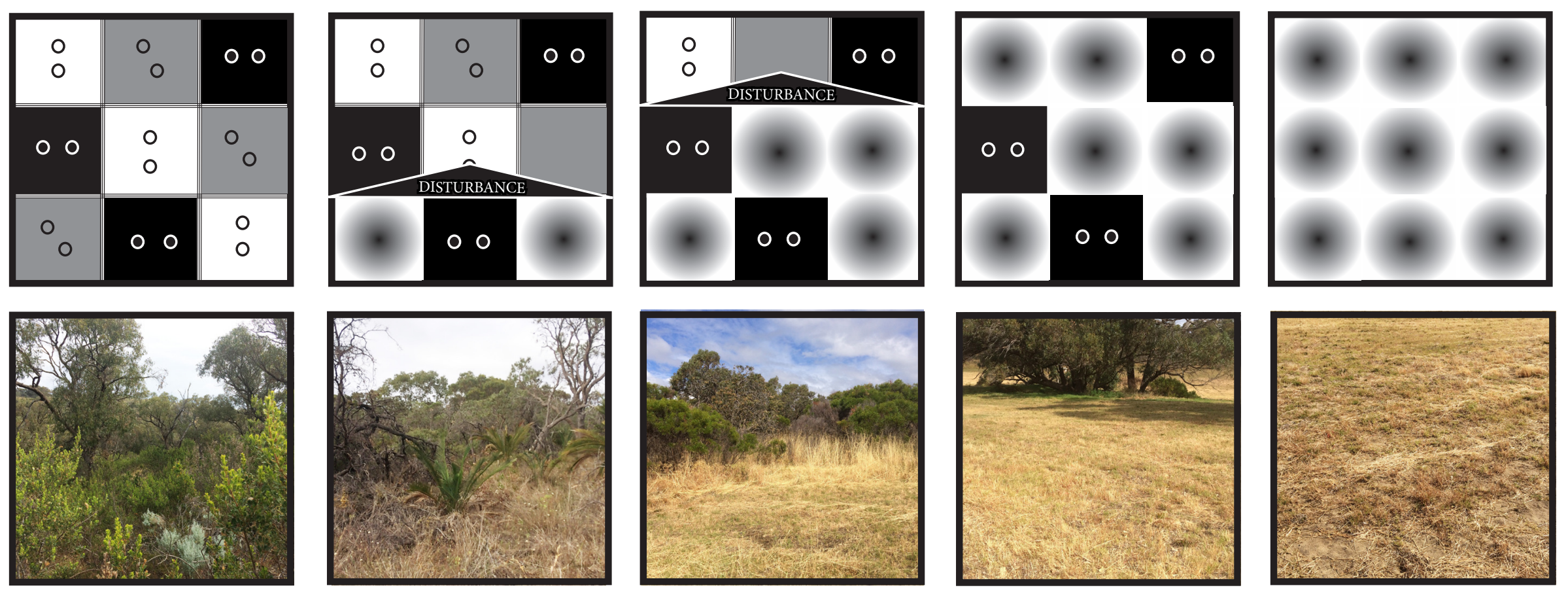